\title{
Kernos
}

Revue internationale et pluridisciplinaire de religion grecque antique

16 | 2003

Varia

\section{O. SALOMIES (éd.), The Greek East in the Roman}

\section{Context}

\section{Vinciane Pirenne-Delforge}

\section{OpenEdition \\ Journals}

\section{Édition électronique}

URL : http://journals.openedition.org/kernos/852

DOI : $10.4000 /$ kernos.852

ISSN : 2034-7871

\section{Éditeur}

Centre international d'étude de la religion grecque antique

Édition imprimée

Date de publication : 1 janvier 2003

Pagination : 380

ISSN : 0776-3824

\section{Référence électronique}

Vinciane Pirenne-Delforge, « O. salomies (éd.), The Greek East in the Roman Context », Kernos [En ligne], 16 | 2003, mis en ligne le 14 avril 2011, consulté le 24 septembre 2020. URL : http:// journals.openedition.org/kernos/852; DOI : https://doi.org/10.4000/kernos.852 
scolaire, dont un des buts, comme le dit l'A. elle-même, est de présenter le texte et de regrouper les informations qui y sont contenues, il reste encore bien des zones d'ombre autour de ces textes qui « offrent un vaste champ d'études ».

Carine Van Liefferinge (Université libre de Bruxelles

Olli Salomies (éd.), The Greek East in the Roman Context. Proceedings of a. colloquium organised by the Finnish Institute at Athens, May 21 and 22, 1999, Helsinki, 2001. 1 vol. $17,5 \times 25 \mathrm{~cm}$, II +217 p., 5 pl. (Papers and Monographs of the Finnish Institute at Athens, 7). ISBN : 951-98806-0-7.

L'analyse de l'impact du pouvoir romain sur la Méditerranée orientale - en ce compris la Grèce - a connu ces dernières années une recrudescence d'intérêt et donc une efflorescence de publications, que ce soient des monographies, des articles ou des actes de colloques. Ces Actes sont un bon reflet de l'actualité d'une telle préoccupation et réunissent un bel ensemble de spécialistes, confirmés ou à venir. Les questions religieuses ne sont toutefois pas nombreuses, ce qui justifie la brièveté de cette notice. Épinglons donc la contribution de J.-L. Ferrary (Rome et la géographie de l'bellénisme: réflexions sur. 'bellènes' et 'panbellènes' dans les inscriptions d'époque romaine) qui touche notamment à la question du Panhellénion; les deux inscriptions qui constituent le départ de cette étude ont été découvertes dans le sanctuaire de Claros et touchent à des actions

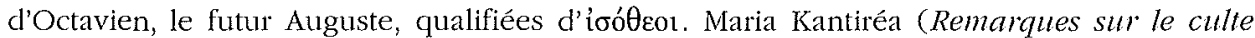
de la domus Augusta en Achaïe de la mont d'Auguste à Néron) offre une brève contribution à l'étude du culte dynastique dans la province d'Achaïe, en tentant une datation des diverses avancées en cette matière. Mika Kajava (Vesta and Atbens) pose quant à lui un très intéressant problème d'histoire religieuse : la Vesta romaine, que l'interpretatio graeca identifie comme une Hestia, avait-elle une place à Athènes, et, si oui, quel était la part de l'idéologie proprement romaine - au-delà d'un simple opportunisme politique des Athéniens - qui avait présidé à cette implantation? La démonstration est longue et parfois touffue, mais l'hypothèse d'une localisation sur l'Acropole, dans le monoptère d'Auguste et de Rome à partir de 12 av. J.-C. a de bons arguments en sa faveur. S. Follet et D. Peppas Delmousou (Les dédicaces cborégiques d'époque flavienne et antonine à Athènes), dans une contribution essentiellement épigraphique, fournissent le corpus (avec quelques photographies excellentes) remis à jour de ces inscriptions qui étaient autant de dédicaces en prose ou en vers illustrant les monuments supportant le trépied donné au vainqueur des choeurs dithyrambiques des Grandes Dionysies. P. Themelis (Roman Messene. The Gymnasium) rend compte de ses fouilles sur ce site et fait notamment référence à un certain nombre de statues divines qui s'élevaient dans le gymnase et à des inscriptions honorifiques mentionnant des fondations religieuses ou des sacrifices. D'autres contributions concernent le rapport de la 'Grèce de l'est' à la mémoire de la république romaine (C.P. Jones), les élites municipales des colonies romaines d'Achaïe (A.D. Rizakis), la famille de Théophane de Mytilène (K. Buraselis), la première province romaine de Syrie (M. Sartre, avec en annexe la liste des gouverneurs de Syrie entre 64 et 31), les inscriptions honorifiques pour les sénateurs romains en 'Grèce de l'est' (O. Salomies) et les cognomina latins dans cette région (H. Solin). Des index soigneux complètent utilement cet ensemble.

Vinciane Pirenne-Delforge (FNRS - Université de Liège)

Susan Alcock, John F. Cherry, Ja's Elsner (éds), Pausanias. Travel and Memory in Roman Greece, Oxford, University Press, 2001.1 vol. $16 \times 24 \mathrm{~cm}$, xII +379 p., 27 fig. ISBN : 0-19-512816-8.

Comme le soulignent les éditeurs dans leur préface, le présent volume trouve sa légitimation dans le regain d'intérêt dont bénéficie depuis peu Pausanias, un auteur long- 